Research Article

\title{
Genetic diversity and population structure of naturally rare Calibrachoa species with small distribution in southern Brazil
}

\author{
Ana Laura de Wallau John ${ }^{1}$, Geraldo Mäder ${ }^{1}$, Jeferson N. Fregonezi ${ }^{1}$ and Loreta B. Freitas ${ }^{1}$ (iD) \\ ${ }^{1}$ Laboratory of Molecular Evolution, Department of Genetics, Universidade Federal do Rio Grande do Sul, \\ Porto Alegre, RS, Brazil.
}

\begin{abstract}
Calibrachoa is a South-American genus comprising 27 species, several considered endemic or rare; few were subjects in genetic studies. We attempted to generate new data about the phylogenetically related and rare species $C$. eglandulata, C. sendtneriana, C. serrulata, and C. spathulata concerning their genetic diversity and population structure, which, coupled with their known restricted distribution, could help access their conservation status and contribute to the study of the Brazilian biodiversity. We sequenced 88 individuals for plastid intergenic spacers and genotyped 186 individuals for five microsatellite loci. Compared among each other, $C$. sendtneriana and $C$. serrulata presented the highest values of genetic diversity $[\pi \%(\mathrm{sd})=0.23(0.14)$ and $0.43(0.25)$, respectively], followed by $C$. spathulata $[\pi \%(\mathrm{sd})=0.19(0.12)]$ and $C$. eglandulata $[\pi \%(\mathrm{sd})=0.02(0.03)]$. Population differentiation was evident for these latter species, whereas it was not significant for $C$. sendtneriana and $C$. serrulata. Factors such as habitat specificity and fragmentation, pollination syndrome, and life history could explain the observed patterns. Based on the new genetic data and the species' biology, a conservation status was assigned for $C$. sendtneriana and the status of the other three species was reviewed.
\end{abstract}

Keywords: Plastid DNA, microsatellites, threatened species, grasslands, herbaceous species.

Received: October 10, 2017; Accepted: June 12, 2018.

\section{Introduction}

In elevations from 800 to $1,800 \mathrm{~m}$ in southern Brazil, the vegetation forms a mosaic of Araucaria forest and grasslands known as the Brazilian subtropical highland grassland (BSHG) or Campos de Cima da Serra (Iganci et al., 2011). These natural grasslands occur along the Serra Geral formation (Behling, 2002) in Rio Grande do Sul, Santa Catarina (SC), and Paraná (PR) states, and they harbor high levels of plant diversity and endemism (Iganci et al., 2011). Currently, the advance of monocultures, forestry, and urbanization are the most important threats to the region (Behling et al., 2005).

Endemic species are plants that occur in specific habitats and are geographically restricted, but such plants can be sparse or abundant, meaning that they can have different population sizes and spatial arrangements (Rabinowitz, 1981). A common assumption is that endemic species are rare and genetically depleted, presenting low genetic diversity and strong population differentiation (Binks et al., 2015; Ciéslak et al., 2015). However, many examples can be found in the literature that contradict this statement (Hou

Send correspondence to Loreta Brandão de Freitas. Laboratory of Molecular Evolution, Department of Genetics, Universidade Federal do Rio Grande do Sul, Av. Bento Gonçalves 9500, 91501-970 Porto Alegre, RS, Brazil. E-mail: loreta.freitas@ ufrgs.br. and Lou, 2011; Ciéslak et al., 2015; Turchetto et al., 2016). Absent or limited gene flow and inbreeding are putative drivers for the genetic diversity pattern associated with small or restricted population sizes (Ellstrand and Elam, 1993), and several other factors can influence the genetic diversity and population structure of rare species. These include mating system, pollination and seed dispersal vectors, life cycle, habitat specificity, demographic history, and landscape and/or climate changes (Loveless and Hamrick, 1984; Shirk et al., 2014; Ciéslak et al., 2015; Shao et al., 2015).

As genetic diversity is directly linked to species survival via the ability to adapt to environmental changes (Ellstrand and Elam, 1993; Binks et al., 2015), analysis of a species' gene pool is fundamental to identify populations that have high and representative levels of genetic polymorphism. Such knowledge can guide strategies regarding how the population should be managed and how this management should be implemented (Casacci et al., 2014; Ciéslak et al., 2015).

Calibrachoa Cerv. (Solanaceae) is a South American genus of perennial herbs and small shrubs distributed in Argentina, Brazil, Paraguay, and Uruguay, with one species sporadically occurring in North America and Europe (Greppi et al., 2013). The majority of the 27 species as- 
signed to the genus occur in Brazil (Stehmann and Greppi, 2011), where several are endemic and at least five can be considered rare (Fregonezi et al., 2013). Calibrachoa species inhabit open areas, grasslands, and rocky outcrops in subtropical and temperate regions. They have a barochoric seed dispersal system and are self-incompatible except for one species (Tsukamoto et al., 2002; Fregonezi et al., 2013).

The molecular phylogenetic analysis of the genus revealed two main clades corresponding to two subgenera (Fregonezi et al., 2012). In the subgenus Stimomphis, four rare and related species occur exclusively in the highland grasslands in southern Brazil (Figure 1): Calibrachoa eglandulata, $C$. sendtneriana, $C$. serrulata, and $C$. spathulata.

Calibrachoa eglandulata (Figure S1) is a bee-pollinated species with pink flowers (Stehmann and Semir, 1997) that grows in rocky shaded environments and is federally listed as Endangered (Martinelli and Moraes, 2013); the only known occurrence sites for this species are in Urubici municipality, Santa Catarina (SC), Brazil. Calibrachoa sendtneriana (Figure S2) has orange-red flowers, suggesting a bird pollination syndrome (Fregonezi et al., 2013) and currently has no determined conservation status. This species is a small shrub growing in the margins of cloud forests and in rocky outcrops in the middle of grasslands, recorded only in the municipalities of Bom Jardim da Serra and Bom Retiro (SC). Calibrachoa serrulata (Figure S3) is also bird-pollinated (Fregonezi et al., 2013) even though it has magenta-colored flowers, and it grows in cliff protrusions along the hills; currently this species is ranked as Data Deficient (Martinelli and Moraes, 2013). There are records of its occurrence in Bom Jardim da Serra and Lauro Müller municipalities (SC). Calibrachoa spathulata (Figure S4) has magenta to purplish bee-pollinated flowers and it grows on roadsides close to urban areas in five cities located in the states of Paraná and Santa Catarina. It is con-

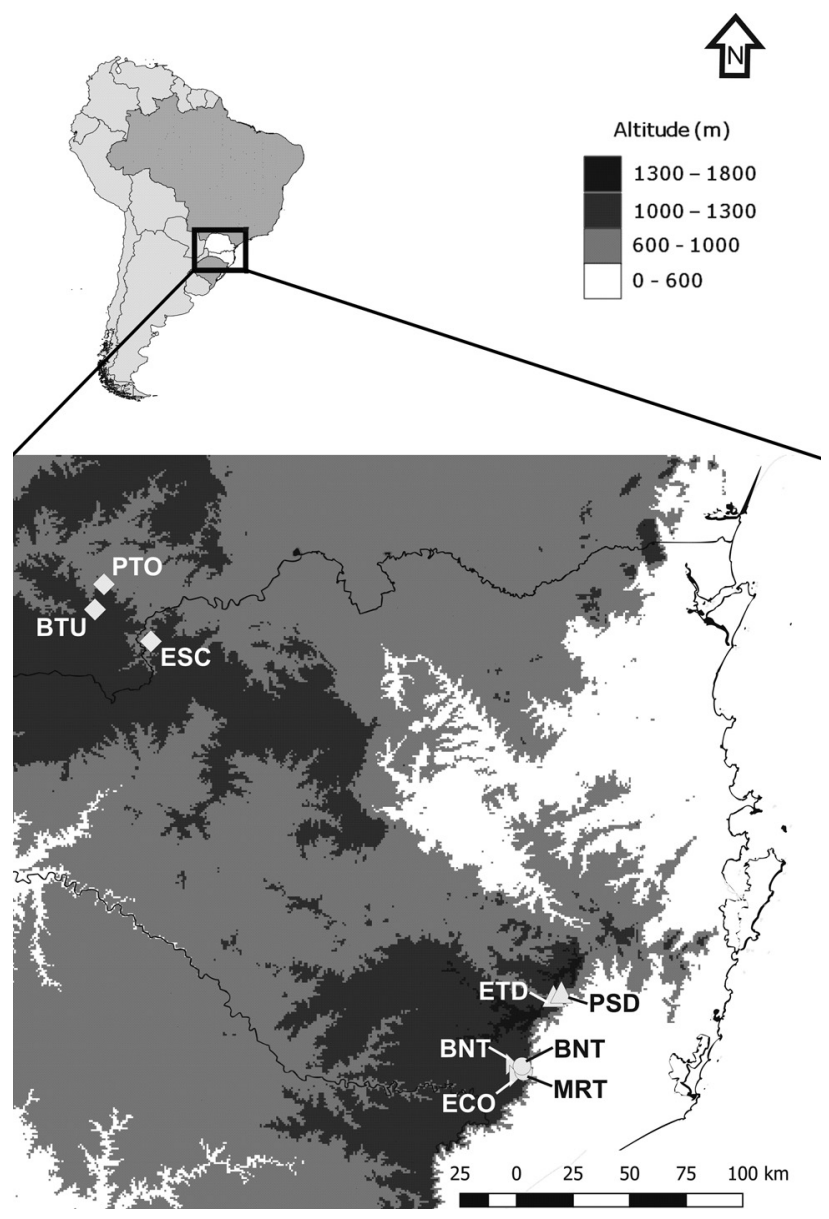

Figure 1 - Geographic distribution of collection locations of four Calibrachoa species: C. eglandulata (triangles); C. sendtneriana (half-diamonds); C. serrulata (circles); and C. spathulata (diamonds). For population codes per species see Table 1 .

Table 1 - Sampling information for four Calibrachoa species.

\begin{tabular}{|c|c|c|c|c|c|}
\hline Species & Population code & Geographic Coordinates & Vouchers* & Sample size (cpDNA) ${ }^{\#}$ & Sample size $(\mathrm{SSR})^{\#}$ \\
\hline \multirow[t]{3}{*}{ C. eglandulata } & & & & 16 & 54 \\
\hline & ETD & $2802^{\prime} 35^{\prime \prime} \mathrm{S} 4924^{\prime} 30^{\prime \prime} \mathrm{W}$ & BHCB104869 & 9 & 40 \\
\hline & PSD & 2801 ' 32 '’s 4922 ' 21' 'W & BHCB104877 & 7 & 14 \\
\hline \multirow[t]{3}{*}{ C. sendtneriana } & & & & 37 & 54 \\
\hline & BNT & $2821^{\prime} 14^{\prime \prime} \mathrm{S} 4934^{\prime} 25^{\prime \prime} \mathrm{W}$ & BHCB116972 & 31 & 31 \\
\hline & $\mathrm{ECO}$ & $2824^{\prime} 31^{\prime \prime} \mathrm{S} 4933^{\prime} 27^{\prime \prime} \mathrm{W}$ & ICN184926 & 6 & 23 \\
\hline \multirow[t]{3}{*}{ C. serrulata } & & & & 18 & 30 \\
\hline & BNT & $2821^{\prime} 46^{\prime \prime} \mathrm{S} 4933^{\prime} 05^{\prime \prime} \mathrm{W}$ & ICN184945 & 8 & 10 \\
\hline & MRT & $2823^{\prime} 16^{\prime \prime} \mathrm{S} 4932^{\prime} 38^{\prime \prime} \mathrm{W}$ & ICN184944 & 10 & 20 \\
\hline \multirow[t]{4}{*}{ C. spathulata } & & & & 17 & 48 \\
\hline & $\mathrm{ESC}$ & 2625 '53's 51 14' $11^{\prime \prime} \mathrm{W}$ & ICN160333 & 6 & 27 \\
\hline & BTU & $2617^{\prime} 12^{\prime \prime} \mathrm{S} 5129^{\prime} 24^{\prime \prime} \mathrm{W}$ & ICN184918 & 6 & 12 \\
\hline & PTO & $2610^{\prime} 19^{\prime \prime} \mathrm{S} 5126^{\prime} 57^{\prime \prime} \mathrm{W}$ & ICN184920 & 5 & 9 \\
\hline
\end{tabular}

* BHCB - Herbarium of Universidade Federal de Minas Gerais, Belo Horizonte, MG, Brazil; ICN - Herbarium of Universidade Federal do Rio Grande do Sul, Porto Alegre, RS, Brazil. ${ }^{\#}$ total number of analyzed individuals per species and per population. 
sidered a Vulnerable species (Martinelli and Moraes, 2013).

All these four Calibrachoa species are known to grow in very few localities and occupy small distribution areas; as it is common among Calibrachoa species, there are no specific studies on pollination or mating systems for these species. Only C. serrulata is not directly affected by anthropogenic pressure, because normally the individuals grow directly on vertical walls of canyons. These species can be considered rare based on their population size and range, and are currently threatened by habitat loss caused by human intervention.

Here, we aimed to estimate the genetic diversity and population structure of these four species and to suggest a new or a reviewed conservation status for each species through the analysis of new and important information. With only three studies published discussing genetic information for Calibrachoa species (Fregonezi et al., 2012, 2013; Mäder et al., 2013), this current study increases the scientific knowledge for this genus and the Brazilian flora, providing useful data for the preservation of these four species.

\section{Materials and Methods}

\section{Sampling and DNA extraction}

For each of the four Calibrachoa species ( $C$. eglandulata, $C$. sendtneriana, $C$. serrulata, and $C$. spathulata), we covered the entire known geographic distribution, visiting all recorded collection sites. For $C$. sendtneriana, no plants were found in the site previously prospected (J.N. Fregonezi, personal observation), resulting in two or three sample collection sites (hereafter called populations) per species (Figure 1, Table 1). Populations of C. eglandulata (ETD and PSD) were located $4 \mathrm{~km}$ apart from each other, whereas $3.2 \mathrm{~km}$ separated $C$. serrulata's populations (BNT and MRT). The C. sendtneriana's BNT and ECO populations were $7.3 \mathrm{~km}$ away from each other. The populations of $C$. spathulata were the most distant from each other: $\mathrm{ESC} v s . \mathrm{BTU}=31.4 \mathrm{~km}, \mathrm{ESC} v s . \mathrm{PTO}=$ $37.6 \mathrm{~km}$, and BTU vs. $\mathrm{PTO}=13.4 \mathrm{~km}$.

Young leaves were collected from each sampled individual, stored in silica gel, and pulverized using liquid nitrogen. DNA extraction was performed following the CTAB (cetyl-trimethylammonium bromide)-based method as described for Calibrachoa species (Fregonezi et al., 2012). Genomic DNA quality was evaluated by horizontal electrophoresis in a $1 \%$ agarose gel stained with $0.001 \%$ GelRed (Biotium, Fremont, CA, EUA) and visualized under ultraviolet light. Concentration and purity were evaluated using a NanoDrop 1000 spectrophotometer (Thermo Fisher Scientific Inc., Waltham, MA, USA) by measuring the absorbance at 260 and $280 \mathrm{~nm}$.

\section{Plastid markers}

The plastid intergenic spacers trnH-psbA (Sang et al., 1997) and trnS-trnG (Hamilton, 1999) were amplified for 88 individuals (Table 1) of four Calibrachoa species. PCR assays were performed using $0.2 \mathrm{mM}$ of each dNTP, $0.16 \mathrm{mM}$ of each primer, $2 \mathrm{mM} \mathrm{MgCl}_{2}, 5 \mathrm{ng}$ of template genomic DNA, 1 U Platinum Taq polymerase (ThermoFisher Scientific Co., Waltham, MA, USA), and 1 reaction buffer (Thermo-Fisher) for a total volume of $25 \mu \mathrm{L}$. Reaction conditions were as follows: $94{ }^{\circ} \mathrm{C}$ for $5 \mathrm{~min}, 35$ cycles of $94^{\circ} \mathrm{C}$ for $1 \mathrm{~min}, 55^{\circ} \mathrm{C}$ for $1 \mathrm{~min}$ and $72^{\circ} \mathrm{C}$ for $1.5 \mathrm{~min}$, finalizing with $72{ }^{\circ} \mathrm{C}$ for $10 \mathrm{~min}$. Sequences obtained in this study were deposited in GenBank (see Table S1 for accession numbers). After amplification, the quality of PCR products was checked by horizontal electrophoresis in a $1 \%$ agarose gel stained with $0.001 \%$ GelRed $^{\mathrm{TM}}$ (Biotium, Freemont, CA, USA) and later purified using PEG 20\% (polyethylene glycol; Sigma-Aldrich Co., St. Louis, MO, USA) according to Dunn and Blattner (1987) and sequenced in a MegaBACE1000 (GE Healthcare Bio Sciences Corp., Piscataway, NY, USA) automatic sequencer according to the manufacturer's instructions and the DYEnamicET Terminator Sequencing Premix Kit (GE Healthcare). For each marker, both forward and reverse strands were checked using the Chromas 2.0 software (Technelysium, Helensvale, Australia), manually aligned and edited using MEGA 6 (Tamura et al., 2013); insertion/deletions events longer than one base pair (bp) were coded as single mutational events.

\section{Nuclear markers}

For all these four species, we initially tested $25 \mathrm{mi}-$ crosatellite loci developed for other Calibrachoa species that presented positive transferability (Silva-Arias et al., 2015; G. Mäder et al., unpublished data). Because only some few of them could be amplified and were polymorphic for all the four species, we used four loci described for C. heterophylla (Che 18, Che 46, Che 59, and Che 34; Silva-Arias et al., 2015) and one for C. pygmaea (Cpy58; G. Mäder et al., unpublished data) to amplify the 186 individuals of the four Calibrachoa species (Table 1). PCR final volume was $\sim 10 \mu \mathrm{L}$ and contained 1 reaction buffer (Thermo-Fisher), $2.0 \mathrm{mM}$ of each dNTP, $2.0 \mathrm{mM}$ of each primer, $50 \mathrm{mM} \mathrm{MgCl}_{2}, 10 \mathrm{ng}$ of template genomic DNA, and $0.5 \mathrm{U}$ Platinum Taq polymerase (Thermo-Fisher). The forward primers were labelled with FAM, NED, HEX or PET-TGT AAA ACG ACG GCC AGT-3' (Schuelke, 2000). Reactions were performed under the following conditions with different annealing temperatures (Ta) for the microsatellites: $94{ }^{\circ} \mathrm{C}$ for $3 \mathrm{~min} ; 35$ cycles of $94^{\circ} \mathrm{C}$ for $20 \mathrm{~s}$; $50{ }^{\circ} \mathrm{C}$ (Che 34), $54{ }^{\circ} \mathrm{C}$ (Che18, Che 46 , Che 59 ) or $55^{\circ} \mathrm{C}$ (Cpy 58) for $45 \mathrm{~s}$; and $72{ }^{\circ} \mathrm{C}$ for $1 \mathrm{~min}$, finalizing with $72^{\circ} \mathrm{C}$ for $10 \mathrm{~min}$. PCR products were visualized under ultraviolet light in $2.5 \%$ agarose gel stained with $0.001 \%$ GelRed and 
later purified using isopropanol and 70\% ethanol. The amplified DNA was denatured and size-fractionated using capillary electrophoresis on an Applied Biosystems Genetic Analyser (Thermo-Fisher) with a LIZ (500) molecular size standard (Thermo-Fisher).

\section{Genetic diversity analyses}

The concatenated alignment of the plastid intergenic spacers was used in all analyses that were performed for each species separately. Haplotypes were identified using DNAsp 5.10.01 (Librado and Rozas, 2009) and haplotype evolutionary relationships were estimated using Network 5.0.0.1 (http://www.fluxus-engineering.com/sharenet.htm) via the median-joining method (Bandelt et al., 1999). We performed summary statistics (haplotype and nucleotide diversities) and quantified the partitioning of genetic variation among different populations through AMOVA (Analysis of Molecular Variation - Excoffier et al., 1992) with 1,000 permutations using $F_{\mathrm{ST}}$ (pairwise differences) in Arlequin 3.5.1.2 (Excoffier and Lischer, 2010). Additionally, we used $G_{\mathrm{ST}}$ standardized method (Hedrick, 2005) with 1,000 permutations to quantify the genetic diversity as performed in DNAsp. The Fu's Fs (Fu, 1997) and Tajima's D (Tajima, 1989) neutrality tests were also performed in Arlequin. The Bayesian skyline plot (BSP - Drummond et $a l ., 2005$ ) analysis was performed using Beast 1.8 (Drummond et al., 2012) for each species individually in order to evaluate the historical population size. For this analysis, a relaxed molecular clock model with a mean substitution rate of $2.810^{-9}$ per site per year (standard deviation $5.410^{-11}$ ) according to Lorenz-Lemke et al. (2010) and HKY nucleotide substitution model as estimated in JModelTest (Darriba et al., 2012) were used as priors. Markov Chain Monte Carlo was performed for 100,000,000 steps, sampling every 10,000 steps. Tracer 1.6 (Rambaut et al., 2013) was employed to compute the BSP and to inspect for convergence. We searched the literature on related species in order to compare haplotype and nucleotide diversity values with published data.

For microsatellite markers, the quality and size of the nuclear genotyped alleles were checked by using GeneMarker 2.2.0 (http://www.softgenetics.com/GeneMarker.php). The number of alleles per locus, allelic richness, $G_{\mathrm{ST}}$, and fixation index $(F)$ were estimated in FSTAT 2.9.3.2 (Goudet, 1995). Cervus 3.07 (Marshall et al., 1998; Kalinowski et $a l ., 2007)$ was used to estimate the frequency of null alleles, the levels of observed $\left(\mathrm{H}_{\mathrm{O}}\right)$ and expected $\left(\mathrm{H}_{\mathrm{E}}\right)$ heterozygosity, and significant deviations from the Hardy-Weinberg equilibrium (HWE) were assessed after Bonferroni correction $(\mathrm{p}=0.05)$.

The AMOVAs were conducted using 1,000 permutations among collection sites and $F_{\mathrm{ST}}$ (pairwise differences) using Arlequin, and we also performed a Principal Coordinates Analysis (PCoA) using GenAlEx 6.5 (Peakall and
Smouse, 2012) based on a distance matrix (proportion of shared alleles) generated in MSA 4.05 (Dieringer and Schlötterer, 2003). In addition, the existence and number of genetic clusters for each species were inferred using STRUCTURE 2.3.4 (Pritchard et al., 2000), and the best K value was estimated through $\Delta \mathrm{K}$ (Evanno et al., 2005) in CLUMPAK ONLINE (http://clumpak.tau.ac.il/contact.html). STRUCTURE runs were performed using $10^{6}$ Markov Chain Monte Carlo repetitions after a $10^{5}$ burn-in period and ten iterations per $\mathrm{K}$, evaluating different numbers of possible clusters per species (1-6 for C. eglandulata, 1-5 for $C$. sendtneriana, and $C$. serrulata, and 1-8 for $C$. spathulata) to cover the number of different collection sites. The resulting bar plot from the summarized iterations for the best $\mathrm{K}$ was generated using CLUMPAK ONLINE.

\section{Conservation status assessment}

We used the International Union for the Conservation of Nature (IUCN, 2017) Criteria and the online tool GeoCAT (Bachman et al., 2011) to estimate the conservation status of $C$. sendtneriana and review the current status of C. eglandulata, C. serrulata, and C. spathulata. The GeoCAT input file included coordinates retrieved from SpeciesLink (CRIA, 2017) and our databank. Regarding the SpeciesLink data, we removed coordinates associated with misidentifications as well as those with the same collection number. IUCN Criteria were applied considering simultaneously our population structure results and population size estimates based on the number of individuals collected per site during field expeditions.

\section{Results}

\section{Plastid markers}

The combined cpDNA (trnG-trnS and psbA-trnH) yielded a 1,181-bp sequence for each species in independent alignments, with two variable sites for C. eglandulata, 15 for $C$. sendtneriana, 11 for $C$. serrulata, and seven for $C$. spathulata. Nucleotide diversity values ranged from 0.02 to $0.43 \%$ (Table 2 ) and haplotype diversity ranged from 0.24 to $0.93 \%$ on average among species. $C$. eglandulata had the lowest values per species for both statistics $(\pi=0.02 \%$; $h=$ 0.24 ), with these results visible in the haplotype network (Figure 2A) where the haplotypes $\mathrm{H} 2$ and $\mathrm{H} 3$ present only one mutation in relation to $\mathrm{H} 1$. The highest value for nucleotide diversity per species was seen in C. serrulata $(\pi=$ $0.43 \%$ ), whereas the highest value of $h$ was in $C$. spathulata $(h=0.93)$. Considering populations individually, PSD of $C$. eglandulata was monomorphic and MRT of C. serrulata presented the highest nucleotide diversity $(\pi=0.36)$, especially concerning the high number of mutations that separate $\mathrm{H} 1$ (exclusive to MRT) from the other haplotypes in this species. PTO population of $C$. spathulata showed the highest haplotype diversity $(h=0.80)$. The number of haplotypes among species ranged from three ( $C$. 
Table 2 - Genetic variability and populations based on concatenated $\operatorname{trnH}$-psbA/trnS-trnG for four Calibrachoa species.

\begin{tabular}{|c|c|c|c|c|c|}
\hline Species/Populations & Haplotypes (AF) & $\pi \%(\mathrm{sd})$ & $H(\mathrm{sd})$ & Fs & $\mathrm{D}$ \\
\hline C. eglandulata & H1 (14), H2 (1), H3 (1) & $0.02 \pm 0.03$ & $0.24 \pm 0.14$ & -1.6 & -1.2 \\
\hline ETD & $\mathrm{H} 1, \mathrm{H} 2, \mathrm{H} 3$ & $0.04 \pm 0.04$ & $0.42 \pm 0.19$ & & \\
\hline PSD & $\mathrm{H} 1$ & - & - & & \\
\hline C. sendtneriana & $\begin{array}{l}\text { H1 (5), H2 (1), H3 (2), H4 (14), H5 (1), H6 (8), } \\
\text { H7 (1), H8 (1), H9 (1), H10 (1), H11 (2) }\end{array}$ & $0.23 \pm 0.14$ & $0.80 \pm 0.05$ & -2.1 & -0.8 \\
\hline BNT & H1, H2, H3, H4, H6, H7, H8, H9, H10, H11 & $0.13 \pm 0.09$ & $0.76 \pm 0.06$ & & \\
\hline ECO & $\mathrm{H} 1, \mathrm{H} 5$ & $0.27 \pm 0.20$ & $0.40 \pm 0.24$ & & \\
\hline C. serrulata & H1 (7), H2 (6), H3 (3), H4 (2) & $0.43 \pm 0.25$ & $0.74 \pm 0.06$ & -5.3 & -2.2 \\
\hline BNT & $\mathrm{H} 2, \mathrm{H} 3, \mathrm{H} 4$ & $0.15 \pm 0.11$ & $0.75 \pm 0.10$ & & \\
\hline MRT & $\mathrm{H} 1, \mathrm{H} 2$ & $0.36 \pm 0.22$ & $0.47 \pm 0.13$ & & \\
\hline C. spathulata & $\begin{array}{l}\mathrm{H} 1 \text { (2), H2 (2), H3 (2), H4 (3), H5 (3), H6 (1), H7 } \\
(1), \mathrm{H} 8 \text { (2), H9 (1) }\end{array}$ & $0.19 \pm 0.12$ & $0.93 \pm 0.03$ & $-3.4^{\#}$ & 0.0 \\
\hline ESC & $\mathrm{H} 5, \mathrm{H} 8, \mathrm{H} 9$ & $0.15 \pm 0.12$ & $0.74 \pm 0.16$ & & \\
\hline BTU & H1. H4, H7 & $0.08 \pm 0.07$ & $0.73 \pm 0.16$ & & \\
\hline PTO & H2, H3, H6 & $0.08 \pm 0.08$ & $0.80 \pm 0.16$ & & \\
\hline
\end{tabular}

(AF) - absolute frequency; $\pi$ - nucleotide diversity; $h$ - haplotype diversity; sd - standard deviation; Fs - Fu's Fs; D - Tajima's D; ${ }^{\#}$ - significant value at p $\leq$ 0.02

eglandulata) to 11 (C. sendtneriana). In C. eglandulata, the two populations shared the most frequent haplotype, whereas two haplotypes were observed in only one individual each from the ETD population (Table 2); in $C$. sendtneriana, the most frequent haplotype was exclusive to the BNT population, and the BNT and ECO populations shared only one haplotype (Figure 2B). The individuals of two populations of $C$. serrulata shared only one haplotype (Figure 2C). All populations of C. spathulata presented exclusive haplotypes; there were three haplotypes in each population, and all of them were found in low frequencies (Table 2).

According to the AMOVA results (Table 3), no population structure was detected in C. eglandulata; complete genetic diversity was attributed to the divergence among individuals within populations. For $C$. sendtneriana, the majority of diversity was found among populations (70\%), whereas for $C$. serrulata and $C$. spathulata similar values $(\sim 50 \%)$ of genetic diversity were found among and within populations. In the case of $C$. spathulata, the genetic partitioning percentages found were related to the similar values obtained for $\pi$ and $h$ in each population (Table 2), with the resultant strong and varied population structure denoted in the haplotype network (Figure 2D).

The $F_{\mathrm{ST}}$ values (Table 3 ) were higher than $G_{\mathrm{ST}}$ 's, which can be related to the mutation rate of the markers employed in our study. The presence of population structure for $C$. spathulata was evident in both methods $\left(F_{\mathrm{ST}}=0.53\right.$ and $\left.G_{\mathrm{ST}}=0.289\right)$, as well as the lack of population structure in $C$. eglandulata $\left(F_{\mathrm{ST}}=-0.03\right.$ and $\left.G_{\mathrm{ST}}=0.029\right)$. In $C$. serrulata, the $F_{\mathrm{ST}}$ value was similar to $C$. spathulata's but $G_{\mathrm{ST}}$ indicated a moderate population structure $\left(G_{\mathrm{ST}}=\right.$
0.189). For $C$. sendtneriana, $F_{\mathrm{ST}}$ pointed to strong population structure whereas $G_{\mathrm{ST}}$ indicated a moderate structure $\left(F_{\mathrm{ST}}=0.70\right.$ and $G_{\mathrm{ST}}=0.173$, respectively). All values for neutrality tests, except for Fu's Fs in $C$. spathulata, were non-significant (Table 2).

The demographic patterns of each species as assessed through the Bayesian skyline plot analysis (Figure S5) indicated stable population sizes for $C$. eglandulata (despite high standard deviations probably due to low genetic diversity) and C. spathulata. C. serrulata data suggested a population decrease in the last 100,000 years (also with high standard deviation values). For $C$. sendtneriana, the BSP indicated a population expansion in the last 100,000 years, which was compatible with the star-like shape of the haplotype network (Figure 2B). However, these results should be considered with caution due to the large credibility intervals associated with population genetic diversity estimates.

\section{Nuclear markers}

The numbers of alleles per locus and per species ranged from three to 27 and the locus that presented the highest number of alleles was Che46 in all species. In general, the proportion of null alleles was low among loci and species $(0.01 \%$ to $0.84 \%)$, and Che 18 was the locus that showed the highest number of null alleles for all species. At least one locus per species deviated from HWE after Bonferroni correction $(\mathrm{p}=0.05)$, indicating a heterozygotes deficit (Table S3).

The mean number of alleles per locus among the five microsatellite loci varied from 8.2 (C. serrulata) to 12.6 (C. sendtneriana) (Table 4). Allelic richness ranged from 7.7 


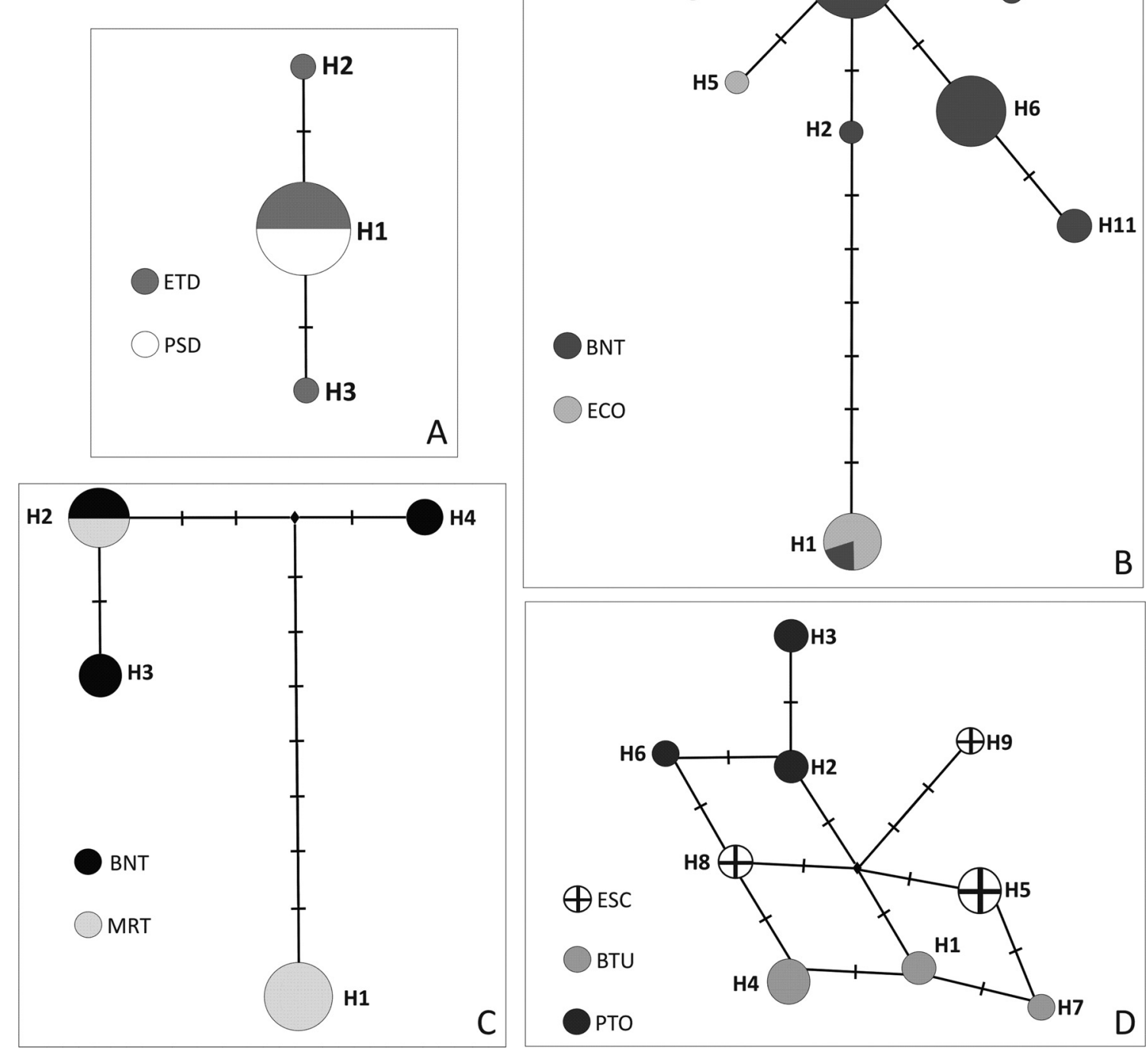

Figure 2 - Evolutionary relationships of plastid haplotypes found in four Calibrachoa species (A) C. eglandulata; (B) C. sendtneriana; (C) C. serrulata; and (D) C. spathulata haplotypes. The circles represent haplotypes, and the diameter is proportional to the frequency across analyzed individuals per spe-

Table 3 - Population structure based on plastid and microsatellite markers through AMOVA, $F_{\mathrm{ST}}$, and $G_{\mathrm{ST}}$ analyses.

\begin{tabular}{llcccc}
\hline & & \multicolumn{3}{c}{ Source of variation } \\
\cline { 3 - 6 } & & Among Populations & Within Populations & $F_{\text {ST }}$ & $G_{\text {ST }}$ \\
\hline cpDNA & C. eglandulata & 0.0 & 100.0 & -0.03 & 0.03 \\
& C. sendtneriana & 70.0 & 30.0 & 0.70 & 0.17 \\
& C. serrulata & 53.8 & 46.2 & 0.54 & 0.19 \\
SSR & C. spathulata & 52.6 & 47.4 & 0.53 & 0.29 \\
& C. eglandulata & 18.0 & 82.0 & 0.18 & 0.18 \\
& C. sendtneriana & 1.6 & 98.4 & 0.02 & 0.02 \\
& C. serrulata & 9.3 & 90.7 & 0.09 & 0.11 \\
& C. spathulata & 24.3 & 75.7 & 0.24 & 0.25 \\
\hline
\end{tabular}

cpDNA - concatenated trnH-psbA/trnS-trnG; SSR - five microsatellite nuclear loci. 
Table 4 - Genetic diversity and demographic indices for four Calibrachoa species based on nuclear microsatellites and populations.

\begin{tabular}{|c|c|c|c|c|c|c|c|}
\hline Species/Population & & $\mathrm{N}$ & $\mathrm{A} / \mathrm{L}$ & $\mathrm{AR}$ & $H_{O}$ & $H_{E}$ & $F$ \\
\hline \multirow[t]{3}{*}{ C. eglandulata } & & 54 & 9.2 & 7.7 & 0.48 & 0.59 & $0.19 *$ \\
\hline & ETD & 40 & 8.2 & 6.2 & 0.46 & 0.55 & $0.16^{*}$ \\
\hline & PSD & 14 & 3.4 & 3.4 & 0.53 & 0.54 & 0.02 \\
\hline \multirow[t]{3}{*}{ C. sendtneriana } & & 54 & 12.6 & 10.4 & 0.60 & 0.76 & $0.21 *$ \\
\hline & BNT & 31 & 9.8 & 9.2 & 0.60 & 0.77 & $0.23 *$ \\
\hline & ECO & 23 & 9 & 8.8 & 0.59 & 0.73 & $0.19 *$ \\
\hline \multirow[t]{3}{*}{ C. serrulata } & & 30 & 8.2 & 7.8 & 0.45 & 0.64 & $0.31 *$ \\
\hline & BNT & 10 & 5.2 & 4.9 & 0.50 & 0.59 & 0.16 \\
\hline & MRT & 20 & 7 & 5.1 & 0.42 & 0.62 & $0.33 *$ \\
\hline \multirow[t]{4}{*}{ C. spathulata } & & 48 & 9.8 & 9.1 & 0.43 & 0.60 & $0.41 *$ \\
\hline & ESC & 27 & 6.8 & 3.3 & 0.40 & 0.58 & $0.31 *$ \\
\hline & BTU & 12 & 5 & 3.5 & 0.44 & 0.62 & $0.31 *$ \\
\hline & РTO & 9 & 3.6 & 2.8 & 0.44 & 0.60 & 0.29 \\
\hline
\end{tabular}

$\mathrm{N}$ - Number of individuals A/L - Alleles per Locus; AR - Allelic Richness; $\mathrm{H}_{\mathrm{O}}$ - Observed Heterozygosity; $\mathrm{H}_{\mathrm{E}}$ - Expected Heterozygosity; F - Fixation In$\operatorname{dex} * \mathrm{p}<0.05$.

(C. eglandulata) to 10.4 (C. sendtneriana). The fixation in$\operatorname{dex}(\mathrm{F})$ values were significant for all species and populations except PSD (C. eglandulata), BNT (C. serrulata), and PTO (C. spathulata).

Based on the five microsatellite loci (Table S3), the four Calibrachoa species presented higher genetic diversity within populations than among populations. The highest divergence among populations was observed in $C$. spathulata $(24.3 \%)$, and the lowest value was seen in $C$. sendtneriana $(1.6 \%)$, with this same pattern recovered in $F_{\mathrm{ST}}$ and $G_{\mathrm{ST}}$ estimates for both species (Table 3 ): $F_{\mathrm{ST}}=0.24$ and $G_{\mathrm{ST}}=0.25$ for the former, and $F_{\mathrm{ST}}=0.02$ and $G_{\mathrm{ST}}=$ 0.02 for the latter. $C$. eglandulata presented moderate values of $F_{\mathrm{ST}}$ and $G_{\mathrm{ST}}$, and for $C$. serrulata a slight indication of population structure is suggested, with $F_{\mathrm{ST}}<G_{\mathrm{ST}}$. PCoA analysis (Figure 3A-D) detected a population structure in C. eglandulata and identified ETD and PSD as differentiated; in C. spathulata the individuals were grouped into their respective populations, and in C. serrulata some individuals from one population were positioned closer to individuals from another population than those from their own population. Absence of population structure was found for C. sendtneriana.

The genetic clustering based on STRUCTURE analysis and best $\mathrm{K}$ values (Figure S6) revealed just one genetic component for each $C$. serrulata and $C$. sendtneriana, suggesting no differentiation between populations in these species; there were three components in C. eglandulata and four in C. spathulata. For C. eglandulata, ETD individuals presented different proportions of each component, whereas individuals from PSD were more homogeneous, predominantly presenting the less frequent component seen in ETD. Individuals from the PTO population of $C$. spathulata were homogeneous and presented only one ge- netic component, whereas individuals from ESC and BTU displayed the four genetic components in different proportions.

\section{Conservation status assessment}

Having increased the amount of information concerning the geographical distribution of these four species, we re-evaluated their conservation status according the IUCN (2017) criteria and suggest they can be updated as follow: the conservation status of $C$. eglandulata was unaltered, and the species remains categorized as Endangered [EN $\mathrm{B} 1+2 \mathrm{ab}$ (ii, iii)]; item ii was added because the species presents a continued decline in its area of occupancy (AOO $=16 \mathrm{~km}^{2}$ ) due to advances in the construction of a roadway. Moreover, C. eglandulata inhabits a highly fragmented habitat with loss of quality and area and is found in only two locations.

Calibrachoa sendtneriana was categorized as Endangered (EN D) because fewer than 250 mature individuals were found. This estimate was based on the number of individuals sampled per collection site throughout ten years of field expeditions. Fragmentation of the species distribution was also considered.

The conservation status of $C$. serrulata was reviewed, and the species is now categorized as Vulnerable (VU D2) because of its restricted $\mathrm{AOO}=12 \mathrm{~km}^{2}$ and the small number of locations where these individuals can be found.

The status of $C$. spathulata was also changed; the species is now categorized as Endangered [EN B1+2ab(iii)] due to the $\mathrm{AOO}=44 \mathrm{~km}^{2}$ and the extent of occurrence $(E O O)=\sim 1300 \mathrm{~km}^{2}$. The fragmentation of habitat and the formation of subpopulations along with habitat quality loss caused by urbanization and land usage contributed to the increased threat of species survival. 

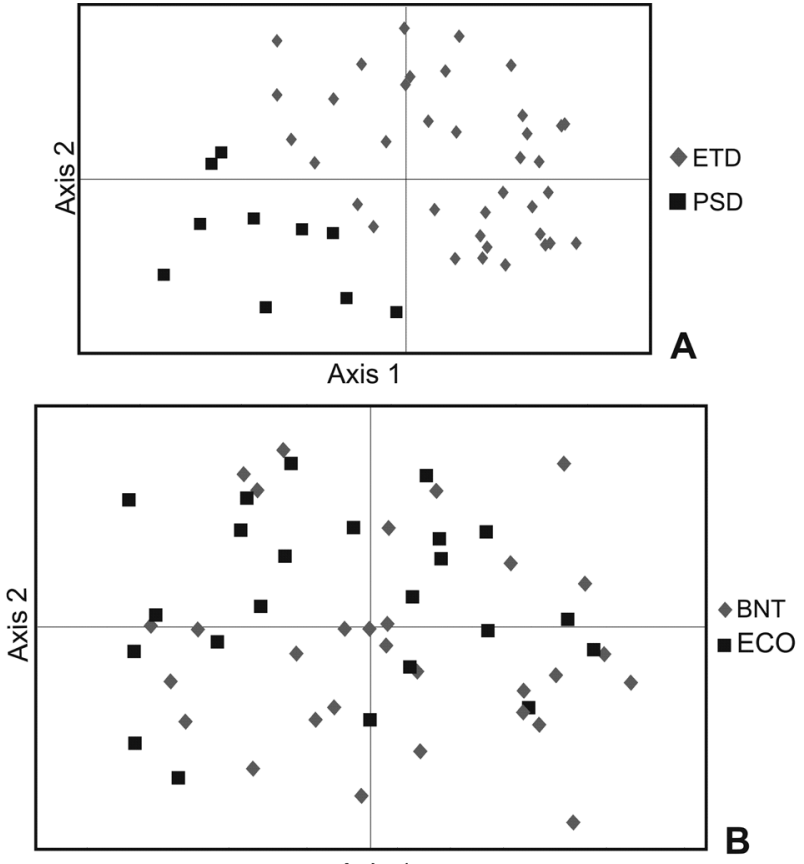

Axis 1
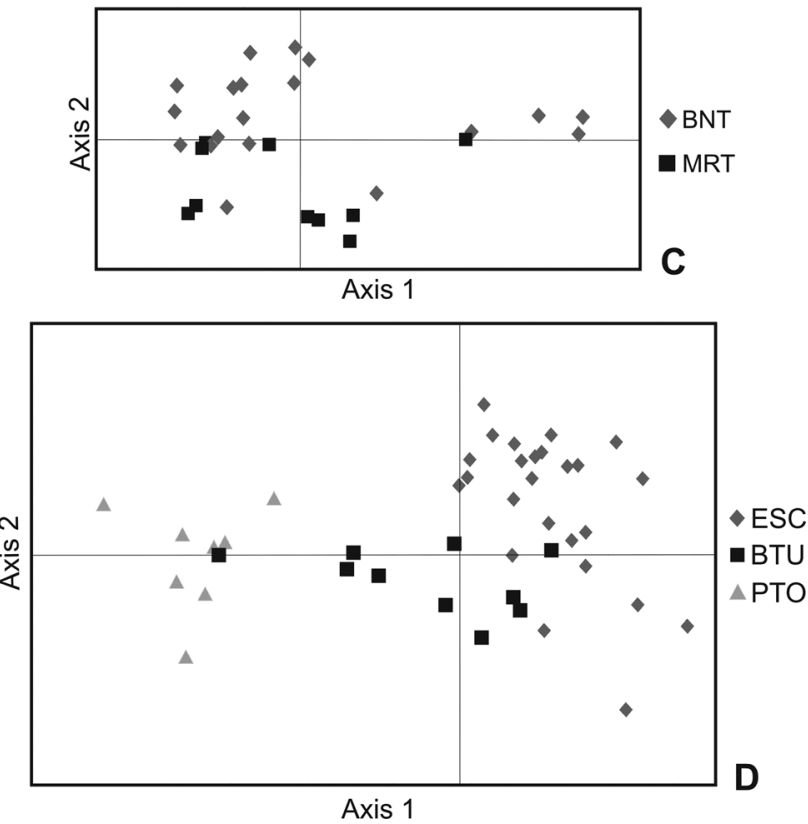

Figure 3 - Ordination of individual microsatellite profiles of four Calibrachoa species in a principal coordinate analysis (PCoA) with the first two vectors per species: (A) C. eglandulata; (B) C. sendtneriana; (C) C. serrulata; and (D) C. spathulata. Individuals are labeled according to the legend.

\section{Discussion}

Rare species can be described as naturally rare or old rare species (Ciéslak et al., 2015), and be associated with singular environments or geographical distribution. The BSHG occupies small and isolated areas (Behling, 2002), with grass vegetation covering the hilltops and Araucaria forest dominating the protected valleys (Safford, 1999). The relationship between grassland and forest during the Quaternary climate changes in this region is well documented through pollen records (Behling, 2002) and phylogeographic studies, especially in Petunia (Lorenz-Lemke et al., 2010) and Calibrachoa (Fregonezi et al., 2013).

Shifts in vegetation range, particularly the grassland expansion during the Pleistocene glacial periods, allowed the ancestral dispersion of Petunia (Reck-Kortmann et al., 2014), whereas the geographical isolation caused by contraction of open fields during the interglacial periods drove diversification (Lorenz-Lemke et al., 2010). Similar patterns have been suggested to explain the distribution of Calibrachoa highland species (Fregonezi et al., 2012, 2013).

Despite the general consensus that species that are naturally rare present structured populations and low genetic diversity (Gitzendanner and Soltis, 2000), some rare species show high genetic diversity and little or no interpopulation differentiation (Turchetto et al., 2016).

Here, we presented plastid and nuclear genetic data for four narrowly endemic, rare, and threatened Calibrachoa species. The data revealed different levels of genetic diversity and population structure between markers and across species. Population size and reduced distribution seem not to have influenced the genetic diversity for $C$. serrulata, which presented nucleotide diversity similar to species with a large geographic distribution such as $C$. heterophylla and $P$. integrifolia spp. integrifolia (Table S2). C. serrulata also showed high nuclear genetic diversity despite having the lowest value of allele richness among the four studied Calibrachoa species, which suggests that the high genetic diversity is not a consequence of ancestral polymorphisms (Jakob and Blattner, 2006) but rather is an inherent trait of this species.

Factors such as the type of pollination, mating system, seasonality of pollination at community level, and longevity of flowers may influence gene flow patterns, and the gene flow impacts directly on the genetic diversity and population structure (Barrett, 2010). Pollination in C. serrulata is performed by hummingbirds (Fregonezi et al., 2012), which favors pollen exchange and outcrossing (Franceschinelli and Bawa, 2000) and long-distance pollen flow, as seen between BNT and MRT populations with the weak or absent population structure recovered in $F_{\mathrm{ST}}$ and $G_{\mathrm{ST}}$ for nuclear markers, PCoA and STRUCTURE analyses. As this is a perennial species, generation overlap could also influence the variability estimates. Despite that, this species presented high fixation index values, particularly in the MRT population. This can be attributed to biparental inbreeding, because the restricted seed dispersal (as seeds fall and germinate close to the mother plant; van der Pijl, 1982) causes intrapopulation spatial genetic structure, and nearneighbor individuals are probably genetically related individuals. Therefore, the high fixation index might reflect co- 
hort mixing rather than an actual increased level of inbreeding. Combined with habitat loss, high levels of inbreeding constitute the main risk for $C$. serrulata.

The plastid genetic diversity indices in $C$. sendtneriana were low to moderate compared to other species (Table S2), whereas this species had the highest values of genetic diversity in nuclear markers among the four analyzed Calibrachoa species. Low diversity in plastid sequences could be a consequence of founder effects (Shirk et al., 2014), small effective size, (Gibson et al., 2008), or severe or continual bottlenecks (Castro et al., 2015), while discrepancies between diversity as estimated through different genomes could be attributed to differences in coalescence time ( $\mathrm{Li}$ et al., 2002). The high genetic diversity observed in $C$. sendtneriana based on microsatellite loci might be explained by gene flow among populations (indirectly indicated by the $F_{\mathrm{ST}}$ and $G_{\mathrm{ST}}$ values; Heller and Siegismund, 2009) promoted by long-distance pollen flow (Ellstrand and Elam, 1993) as this species is bird-pollinated (Fregonezi et al., 2013). Since this species occurs in sympatry with other Calibrachoa species, we cannot discard the possibility of interspecific gene flow, as the species in this genus preserve the intercrossing capacity (Watanabe et al. , 1997) at least in controlled conditions. Fragmented distribution, population size, and potential introgression coupled to habitat degradation could heighten the risk of $C$. sendtneriana extinction.

When we compared markers, C. spathulata showed high to moderate levels of population structure. The populations of this species are located far from each other, limiting the amount of interpopulation gene flow both by seed or pollen dispersion through barochory and bee-mediated. Moreover, this species presented the highest fixation index value, which could be attributed to biparental inbreeding. C. spathulata, especially the PTO population, had a high density of individuals per population that bloomed simultaneously, favoring an increase in pollinator visit rates $\mathrm{Ku}-$ nin, 1997), but because of the high probability of neighboring individuals to be genetically related, pollen exchange in this case can occur between relatives or even parents and offspring since the species is perennial and overlapped generations can be observed in a single blooming season. The main risk factors for this species are habitat loss and fragmented distribution.

Among the studied Calibrachoa species, $C$. eglandulata presented the lowest diversity values for both plastid and nuclear genomes. Based on microsatellites, gene flow between populations is highly reduced or absent because of the geographical distance among populations and the pollinator behavior, since this species is pollinated by solitary bees that can fly only short distances (Stehmann and Semir, 2001). This isolated population structure and the low level of genetic diversity constitute the main threats to C. eglandulata.
The data generated in this study allow different scenarios to be depicted regarding genetic diversity, population size, and geographical range of each Calibrachoa species. $C$. serrulata can be considered a naturally rare species, like Petunia secreta (Turchetto et al., 2016), with restricted geographic range $\left(\mathrm{AOO}=12 \mathrm{~km}^{2} ; \mathrm{EOO}=0.993\right.$ $\mathrm{km}^{2}$ ) but high genetic diversity. Nuclear genetic diversity distributed throughout the two known populations makes both equally important reservoirs of variability, and therefore both should be protected in order to maintain the species' adaptive potential (Binks et al., 2015).

C. sendtneriana also displays little or no population differentiation based on nuclear markers, although BNT population harbors the majority of plastid haplotypes found in this species. Even though it has a larger geographic range $\left(\mathrm{AOO}=36 \mathrm{~km}^{2} ; \mathrm{EOO}=282.9 \mathrm{~km}^{2}\right)$ and the highest allelic richness, $C$. sendtneriana is more prone to habitat loss than C. serrulata because it occurs in areas partially converted into pasture and forest borders directly affected by human interferences, whereas $C$. serrulata grows vertically in the canyon walls and is theoretically more protected from habitat loss.

C. spathulata has the widest geographic range of the four endemic species analyzed here $\left(\mathrm{AOO}=44 \mathrm{~km}^{2}\right.$ and $\left.\mathrm{EOO}=1,264 \mathrm{~km}^{2}\right)$ and presents the largest population size. Considering the strong population structure associated with exclusive haplotypes, conservation actions towards this species should aim to protect all known populations, especially considering that individuals of this species grow on roadsides and other highly urbanized areas. Based on these results and statements by Casacci et al. (2014), each population of C. spathulata could correspond to an evolutionary significant unit (ESU).

The habitat of C. eglandulata is highly fragmented with known populations located on roadsides. Because populations are small and isolated and present low genetic diversity, ex situ conservation may be necessary for this species.

The high fixation index values and heterozygote deficit in the four Calibrachoa species came as no surprise, because the population sizes are small and related individuals tend to grow next to each other due to limited seed dispersal in these species. Combined, these two conditions may be considered as an additional threat to species survival and conservation because the species would tend to lose genetic variability over time due to mating between relatives. We recommend monitoring these species in future years, not only through estimates of population sizes but also with special attention paid to their genetic diversity and potential habitat loss.

The importance of genetic diversity in the maintenance of biological diversity and in evolutionary processes is well established, especially considering the predictions of climate change (Barros et al., 2015). Conservation strategies based on genetic analysis, however, are still limited in 
the BSHG (Overbeck et al., 2007). The species studied herein have low to high levels of plastid genetic diversity compared to related species. We also observed low to high levels of population structure as a result of restricted pollen and seed dispersal based on nuclear markers. Plants presenting biparental inbreeding are more likely to suffer from a loss of alleles, since aggregated populations or even cohorts in a small area can be eliminated by human activity or natural phenomena (Ellstrand, 2014).

In conclusion, the genetic diversity and population structure found in these four rare and narrowly endemic Calibrachoa species may be attributed to historical events, mating systems, and pollinators, whereas the fragmented range and small population sizes are a consequence of habitat loss due to human activities. To ensure the species' survival, actions such as local protection and ex situ conservation would be necessary.

\section{Acknowledgments}

This work was financially supported by the Conselho Nacional de Desenvolvimento Científico e Tecnológico (CNPq), the Coordenação de Aperfeiçoamento de Pessoal de Nível Superior - Brasil (CAPES) - Finance Code 001, and the Programa de Pós-Graduação em Botânica, Universidade Federal do Rio Grande do Sul. We thank C. L. Ribeiro and D.M. Rodrigues for help with IUCN Criteria and GeoCAT analyses, and J.R. Stehmann for plant identification. G.M. was supported by PNPD-CAPES/PPGBotânica, UFRGS.

\section{Conflict of interest}

The authors declare that there is no conflict of interest that could be perceived as prejudicial to the impartiality of the reported research.

\section{Author contributions}

ALWJ and LBF conceived and designed the study; ALWJ, GM and JNF collected the plant material, conducted the experiments, analyzed the data; LBF supplied reagents and equipment; all authors wrote the manuscript and approved its final version.

\section{References}

Bachman S, Moat J, Hill AW, Torre J and Scott B (2011) Supporting Red List threat assessments with GeoCAT: Geospatial conservation assessment tool. Zookeys 150:117-126.

Bandelt HJ, Forster P and Rohl A (1999) Median-joining networks for inferring intraspecific phylogenies. Mol Biol Evol 16:37-48.

Barrett SCH (2010) Understanding plant reproductive diversity. Philos Trans R Soc Lond B Biol Sci 365:99-109.

Barros MJF, Silva-Arias GA, Fregonezi JN, Turchetto-Zolet AC, Iganci JRV, Diniz Filho JAF and Freitas LB (2015) Environmental drivers of diversity in subtropical highland grass- lands: A comparative analysis of Adesmia, Calibrachoa, and Petunia. Perspect Plant Ecol Evol Syst 17:360-368.

Behling H (2002) South and southeast Brazilian grasslands during Late Quaternary times: A synthesis. Palaeogeogr Palaeoclimatol Palaeoecol 177:19-27.

Behling H, Pillar VD and Bauermann SG (2005) Late Quaternary grassland (Campos), gallery forest, fire and climate dynamics, studied by pollen, charcoal and multivariate analysis of the São Francisco de Assis core in western Rio Grande do Sul (Southern Brazil). Rev Palaeobot Palynol 133:235-248.

Binks RM, Millar MA and Byrne M (2015) Not all rare species are the same: Contrasting patterns of genetic diversity and population structure in two narrow-range endemic sedges. Bot J Linn Soc 114:873-886.

Casacci LP, Barbero F and Balletto E (2014) The "Evolutionarily Significant Unit" concept and its applicability in biological conservation. Ital J Zool 81:182-193.

Castro O, Véla E, Vendramin GG, Gargiulo R and Caputo P (2015) Genetic structure in the Genista ephedroides complex (Fabaceae) and implications for its present distribution. Bot J Linn Soc 177:607-618.

Ciéslak E, Ciéslak J, Szelag Z and Ronikier M (2015) Genetic structure of Galium cracoviense (Rubiaceae): A naturally rare species with an extremely small distribution range. Conserv Genet 16:929-938.

Darriba D, Taboada GL, Doallo R and Posada D (2012) JModelTest 2: More models, new heuristics and parallel computing. Nat Methods 9:772.

Dieringer D and Schlötterer C (2003) Microsatellite analyser (MSA): A platform independent analysis tool for large microsatellite data sets. Mol Ecol Notes 3:167-169.

Drummond AJ, Rambaut A, Shapiro B and Pybus OG (2005) Bayesian coalescent inference of past population dynamics from molecular sequences. Mol Biol Evol 22:1185-1192.

Drummond AJ, Suchard MA, Xie D and Rambaut A (2012) Bayesian phylogenetic with BEAUti and the BEAST 1.7. Mol Biol Evol 29:1969-1973.

Dunn IS and Blattner FR (1987) Charons 36 to 40: Multi-enzyme, high capacity, recombination deficient replacement vectors with polylinkers and polystuffers. Nucleic Acids Res 15:2677-2698.

Ellstrand NC (2014) Is gene flow the most important evolutionary force in plants? Am J Bot 101:737-753.

Ellstrand NC and Elam DR (1993) Population genetic consequences of small population size: implications for plant conservation. Annu Rev Ecol Syst 24:217-242.

Evanno G, Regnaut S and Goudet J (2005) Detecting the number of clusters of individuals using the software STRUCTURE: a simulation study. Mol Ecol 14:2611-2620.

Excoffier L and Lischer HEL (2010) Arlequin suite ver 3.5: A new series of programs to perform population genetics analyses under Linux and Windows. Mol Ecol Resour 10:564567.

Excoffier L, Smouse PE and Quattro JM (1992) Analysis of molecular variance inferred from metric distances among DNA haplotypes - Application to human mitochondrial-DNA restriction data. Genetics 131:479-491.

Franceschinelli EV and Bawa KS (2000) The effect of ecological factors on the mating system of a South American shrub species (Helicteres brevispira). Heredity 80:116-123. 
Fregonezi JN, Freitas LB, Bonatto SL, Semir J and Stehmann JR (2012) Infrageneric classification of Calibrachoa (Solanaceae) based on morphological and molecular evidence. Taxon 61:120-130.

Fregonezi JN, Turchetto C, Bonatto SL and Freitas LB (2013) Biogeographical history and diversification of Petunia and Calibrachoa (Solanaceae) in the Neotropical Pampas grassland. Bot J Linn Soc 171:140-153.

$\mathrm{Fu}$ YX (1997) Statistical tests of neutrality of mutations against population growth, hitchhiking and background selection. Genetics 147:915-925.

Gibson JP, Rice SA and Stucke CM (2008) Comparison of population genetic diversity between a rare, narrowly distributed species and a common, widespread species of Alnus (Betulaceae). Am J Bot 95:588-596.

Gitzendanner MA and Soltis PS (2000) Patterns of genetic variation in rare and widespread plant congeners. Am J Bot 87:783-792.

Goudet J (1995) FSTAT version 1.2: A computer program to calculate F-statistics. J Hered 86:485-486.

Greppi JA, Hagiwara JC and Stehmann JR (2013) Novelties in Calibrachoa (Solanaceae) and taxonomic notes on the genus for Argentina. Darwiniana 1:173-187.

Hamilton MB (1999) Four primers pairs for the amplification of chloroplast intergenic regions with intraspecific variation. Mol Ecol 8:513-525.

Hedrick PW (2005) A standardized genetic differentiation measure. Evolution 59:1633-1638.

Heller R and Siegismund HR (2009) Relationship between three measures of genetic differentiation $G_{\mathrm{ST}}, D_{\mathrm{EST}}$ and $\mathrm{G}_{\mathrm{ST}}$ : How wrong have we been? Mol Ecol 18:2080-2083.

Hou Y and Lou A (2011) Population genetic diversity and structure of a naturally isolated plant species, Rhodiola dumulosa (Crassulaceae). PLoS One 6:e24497.

Iganci JRV, Heiden G, Miotto STS and Pennington RT (2011) Campos de Cima da Serra: The Brazilian Subtropical Highland Grasslands show an unexpected level of plant endemism. Bot J Linn Soc 167:378-393

Jakob SS and Blattner FR (2006) A chloroplast genealogy of Hordeum (Poaceae): Long-term persisting haplotypes, incomplete lineage sorting, regional extinction, and the consequences for phylogenetic inference. Mol Biol Evol 23:1602-1612.

Kalinowski ST, Taper ML and Marshall TC (2007) Revising how the computer program CERVUS accommodates genotyping error increases success in paternity assignment. Mol Ecol 16:1099-1106.

Kunin W (1997) Population size and density effects in pollination: Pollinator foraging and plant reproductive success in experimental arrays of Brassica kaber. J Ecol 85:225-234.

Li YC, Korol AB, Fahima T, Beiles A and Nevo E (2002) Microsatellites: Genomic distribution, putative functions and mutational mechanisms: A review. Mol Ecol 11:2453-2465.

Librado P and Rozas J (2009) DnaSP v5: A software for comprehensive analysis of DNA polymorphism data. Bioinformatics 25:1451-1452.

Lorenz-Lemke AP, Togni PD, Mäder G, Kriedt RA, Stehmann JR, Salzano FM, Bonatto SL and Freitas LB (2010) Diversification of plant species in a subtropical region of eastern South American highlands: A phylogeographic perspective on native Petunia (Solanaceae). Mol Ecol 19:5240-5251.
Loveless MD and Hamrick JL (1984) Ecological determinants of genetic structure in plant populations. Annu Rev Ecol Syst 15:65-95

Mäder G, Fregonezi JN, Lorenz-Lemke AP, Bonatto SL and Freitas LB (2013) Geological and climatic changes in quaternary shaped the evolutionary history of Calibrachoa heterophylla, an endemic South-Atlantic species of petunia. BMC Evol Biol 13:178

Marshall TC, Slate J, Kruuk LEB and Pemberton JM (1998) Statistical confidence for likelihood-based paternity inference in natural populations. Mol Ecol 7:639-655.

Overbeck GE, Müller SC, Fidelis A, Pfadenhauer J, Pillar VD, Blanco CC, Boldrini II, Both R and Forneck ED (2007) Brazil's neglected biome: The South Brazilian Campos. Perspect Plant Ecol Evol Syst 9:101-116.

Peakall R and Smouse PE (2012) GenAlEx 6.5: Genetic analysis in Excel. Population genetic software for teaching and research - an update. Bioinformatics 28:2537-2539.

Pritchard JK, Stephens M and Donnelly P (2000) Inference of population structure using multilocus genotype data. Genetics 155:945-959.

Rabinowitz D (1981) Seven forms of rarity. In: Synge H (ed) The biological aspects of rare plant conservation. John Wiley, Chichester, pp 205-217.

Reck-Kortmann M, Silva-Arias GA, Segatto ALA, Mäder G, Bonatto SL and Freitas LB (2014) Multilocus phylogeny reconstruction: New insights into the evolutionary history of the genus Petunia. Mol Phylogenet Evol 81:19-28.

Safford HD (1999) Brazilian Páramos I. An introduction to the physical environment and vegetation of the campos de altitude. J Biogeogr 26:693-712.

Sang T, Crawford DJ and Stuessy TF (1997) Chloroplast DNA phylogeny, reticulate evolution, and biogeography of Paeonia (Paeoniaceae). Am J Bot 84:1120-1136.

Schuelke M (2000) An economic method for the fluorescent labeling of PCR fragments. Nat Biotechnol 18:233-234.

Shao J, Wang J, Xu Y, Pan Q, Shi Y, Kelso S and Lv GS (2015) Genetic diversity and gene flow within and between two different habitats of Primula merrilliana (Primulaceae), an endangered distylous forest herb in eastern China. Bot J Linn Soc 179:172-189.

Shirk RY, Hamrick JL, Zhang C and Qiang S (2014) Patterns of genetic diversity reveal multiple introductions and recurrent founder effects during range expansion in invasive populations of Geranium carolinianum (Geraniaceae). Heredity 112:497-507.

Silva-Arias GA, Mäder G, Bonatto SL and Freitas LB (2015) Novel microsatellites for Calibrachoa heterophylla (Solanaceae) endemic to the South Atlantic Coastal Plain of South America. Appl Plant Sci 3:1500021.

Stehmann JR and Greppi JA (2011) Two new species of Calibrachoa (Solanaceae) from subtropical South America. Phytotaxa 25:31-38

Stehmann JR and Semir J (1997) A new species and new combinations in Calibrachoa (Solanaceae). Novon 7:417-419.

Stehmann JR and Semir J (2001) Biologia reprodutiva de Calibrachoa elegans (Miers) Stehmann \& Semir (Solanaceae). Rev Brasil Bot 24:43-49.

Tajima F (1989) Statistical-method for testing the neutral mutation hypothesis by DNA polymorphism. Genetics 123:585-595. 
Tamura K, Stecher G, Peterson D, Filipski A and Kumar S (2013) MEGA6: Molecular Evolutionary Genetics Analysis Version 6.0. Mol Biol Evol 30:2725-2729

Tsukamoto T, Ando T, Watanabe H, Kokubun H, Hashimoto G, Sakazaki U, Suárez E, Marchesi E, Oyama K and Kao T (2002) Differentiation in the status of self-incompatibility among Calibrachoa species (Solanaceae). J Plant Res 115:185-193.

Turchetto C, Segatto ALA, Mäder G, Rodrigues DM, Bonatto SL and Freitas LB (2016) High levels of genetic diversity and population structure in an endemic and rare species: implications for conservation. AoB Plants 8:plw002.

van der Pijl A (1982) Principles of Dispersal in Higher Plants. $2^{\text {nd }}$ edition. Springer-Verlag, Berlin, 216 pp.

Watanabe H, Ando T, Iida S, Buto K, Tsukamoto T, Kokobun H, Hashimoto G and Marchesi E (1997) Cross-compatibility of Petunia pubescens and P. pygmaea with native taxa of Petunia. J Jpn Soc Hortic Sci 66:607-612.

\section{Internet Resources}

CRIA (2017) SpeciesLink: Sistema de informação distribuído para coleções biológicas, http://splink.cria.org.br/index?\&setlang=en. (accessed 1 July 2017).

IUCN (2017) The IUCN Red List of Threatened Species, version 2017-1, http://www.iucnredlist.org. (accessed 28 June 2017).

Martinelli G and Moraes MA (2013) The Red Book of Brazilian Flora, http://www.santoandre.sp.gov.br/pesquisa/ebooks/372963. PDF (accessed 28 June 2017).

Rambaut A, Suchard MA, Xie D and Drummond AJ (2013)

Tracer, version 1.5, http://beast.bio.ed.ac.uk/Tracer (accessed 28 June 2017).

\section{Supplementary material}

The following online material is available for this article: Table S1 - GenBank accession numbers and plastid haplotypes.

Table S2 - Plastid genetic diversity of Petunia and Calibrachoa species.

Table S3 - Genetic diversity per locus per species for four Calibrachoa species

Figure S1 - Calibrachoa eglandulata.

Figure S2 - Calibrachoa sendtneriana.

Figure S3 - Calibrachoa serrulata.

Figure S4 - Calibrachoa spathulata.

Figure S5 - Bayesian skyline plot showing the fluctuations in effective population size (Ne) over time per Calibrachoa species.

Figure S6 - Population structure and evolutionary relationships of individuals of four Calibrachoa species based on five microsatellite loci;

Associate Editor: Dario Grattapaglia

License information: This is an open-access article distributed under the terms of the Creative Commons Attribution License (type CC-BY), which permits unrestricted use, distribution and reproduction in any medium, provided the original article is properly cited. 